\title{
Cultural adaptation and the Clavien-Dindo surgical complications classification translated to Brazilian Portuguese.
}

\section{Adaptação cultural e teste da escala de complicações cirúrgicas de Clavien-Dindo traduzida para o Português do Brasil.}

luis Fernando Moreira, tCBC-RS'; Marcelo Castro Marçal Pessôa, tCBC-RJ'; Diego Sachet Mattana²; Fernando Fernandes Schmitz²; Bernardo Silveira Volkweis, ACBC-RS²; Jorge luiz Antoniazzi, ACBC-RS33; Liacyr Ribeiro, eCBC-RJ4.

\section{A B S T R A C T}

\begin{abstract}
Objective: to generate a translated and validated version of the Clavien-Dindo Classification of Surgical Complications (CDC) to Brazilian Portuguese (CDC-BR). Methods: the process of translation and adaptation followed the guideline of Beaton et al., 2000. We divided 76 participating surgeons, in different levels of experience, from the Department Surgery of the Hospital de Clínicas de Porto Alegre, into two groups: Group I applied the original version ( $C D C, n=36) ; r$ Group II used the modified version (CDC-BR, $n=40)$. Each group classified 15 clinical cases of surgical complications. We compared performance between the groups (Mann-Whitney test) relating to the level of experience of the surgeon (Kruskal-Wallis test), considering p value $<0.05$ as significant. Results: the performance of the Group II (CDC-BR) was higher, with $85 \%$ accuracy, compared with 79\% of Group I (CDC), p-value $=0.012$. The performance of the groups as for surgeons experience displayed $p=0.171$ for Group I, $p=0.528$ for Group II, and $p=0.135$ for overall performance. Conclusion: we produced a translated and validated version of the CDC for Brazilian Portuguese. The instrument will be a useful tool in the production of evidence on surgical outcomes.
\end{abstract}

Keywords: Surgery/Complications. Quality Improvement. Data Curation. Outcome Assessment (Health Carre). Morbidity.

\section{INTRODUCTION}

$\mathrm{P}$ rograms for quality assessment were developed and implemented in Japan in the postwar period, and are already well established in the industry branch. However, in health care the application of quality concepts has happened more slowly and is still considered incomplete'

In recent decades, there has been an increased demand for care and services in health care. Due to the scarcity of resources, rising costs and a clear change of behavior in clinical practice, indices and quality references have been increasingly sought ${ }^{2,3}$. The interpretation of these data allows comparison of institutional performance across teams and treatment modalities, retrospectively or with follow-up over time. To obtain such parameters, one needs to apply a standardized and reproducible methodology ${ }^{3}$.

For a long time, mortality was the only parameter of assessment of surgical outcomes ${ }^{2,4,5}$. However, with the significant decrease in mortality rates, there was a shift in the focus for morbidity and quality of life $e^{4,6-8}$. Morbidity has been recently reported as a key factor in the analysis of surgical outcomes, particularly among treatment modalities with similar efficacy ${ }^{9}$. Postoperative complications are commonly used factors among many authors who discuss quality in surgery, and their account favors analysis under different aspects and perspectives ${ }^{2,4}$. Although there has been an increased effort towards reports regarding surgical complications, on the other hand there is a huge contradiction in the literature, especially as for their definitions and an objective description of their severity levels ${ }^{10-12}$.

Amid this scenario, Clavien et al. launched in 1992 a proposal for the classification of surgical complications with general principles and definitions for use in cholecystectomy. The treatment required for the surgical complications was the reference point for the differenti-

1 - Programa de Pós-Graduação em Ciências Cirúrgicas da Faculdade de Medicina da Universidade Federal do Rio Grande do Sul, RS, Brasil; 2 - Serviço de Cirurgia do Hospital de Clínicas de Porto Alegre, RS, Brasil; 3 - Departamento de Cirurgia da Faculdade de Medicina da Universidade Federal do Rio Grande do Sul, RS, Brasil; 4. Clínica Liacyr Ribeiro, RJ, Brasil. 
ation of their severity levels. After 12 years, Dindo et al. showed an enhanced version for the classification of surgical complications, based on the first proposal by Clavien et al. Since then, Pierre Alain Clavien group has been conducting a series of studies, recommending new methods to classify surgical complications, testing the reliability of the method and subjecting it to testing in several centers around the world. The tests were applied with instruments produced in English and in German. New perspectives were assessed from the point of view of all parties involved in the decision-making processes of surgical treatments, doctors, nursing staff and patients $23,3,12,13$. From there, it was suggested the need for translation adjustments and cross-cultural adaptation of instruments produced for application in multi-center studies in different countries, with different languages and different cultures ${ }^{9,13,14}$. The concepts proposed by Clavien group have since been adopted by a growing number of authors of various specialties, seeking to discuss and create quality benchmarks in their fields through the report of surgical complications ${ }^{15-23}$.

Although previously tested, accepted and published around the world, the Clavien-Dindo Classification of Surgical Complications (CDC) has not had a translated and tested version for Portuguese in Brazil. Therefore, this work aims to establish and test a version translated into Brazilian Portuguese CDC (CDC-BR), to be used as an instrument faithful to the content of the original classification, thus exceeding any language and cultural barriers.

\section{METHODS}

The process of translation and cross-cultural adaptation of the source instrument, the original $\mathrm{CDC}^{3}$, followed the methodology disclosed by Beaton et al. in 2000. This is a methodology also applied by the American Association of Orthopedic Surgery (AAOS) ${ }^{24,25}$, which comprises five stages $(I-V)$ arranged to maintain and maximize the semantic, idiomatic, experiential and conceptual equivalence between the source instrument and the target one, the CDC-BR. After obtaining the translated version of the $C D C$, the $C D C$-BR was subjected to a validation test. We chose 15 cases of surgical complications, previously tested and published in Clavien's group publi- cations $^{3,12}$, and appraised by 76 surgeons with different levels of experience, randomly divided into two groups, one using CDC and the other, CDC-BR, to classify the surgical complications. This study is part of a research line of the Southern Surgical Oncology Research Group (SSORG) and was approved by the Ethics in Research Committee, under the number 0587/12, Hospital de Clínicas de Porto Alegre, RS, Brazil (Figure 1).

\section{- Stage I (Initial Translation)}

The first step produced the initial translation of the source instrument, $C D C$, into Brazilian Portuguese. Three translators participated at this stage (T1, T2 and T3), one "Expert" (T1) proficient in English and two "Lay" translators, one a Native English speaker (T2) and other proficient in English (T3). Each translator produced an initial version that was used in the next stage.

\section{- Stage II (Summary of Initial Translation)}

The "Expert" translator (T1) gathered and synthesized the initially produced translations (T1, T2 and T3) in order to keep the contents of the source instrument. In this step was then produced the "Literal Translation" (LT).

\section{- Stage III (Back-translation)}

Three other translators that did not participate in the previous stages acted at this stage, one

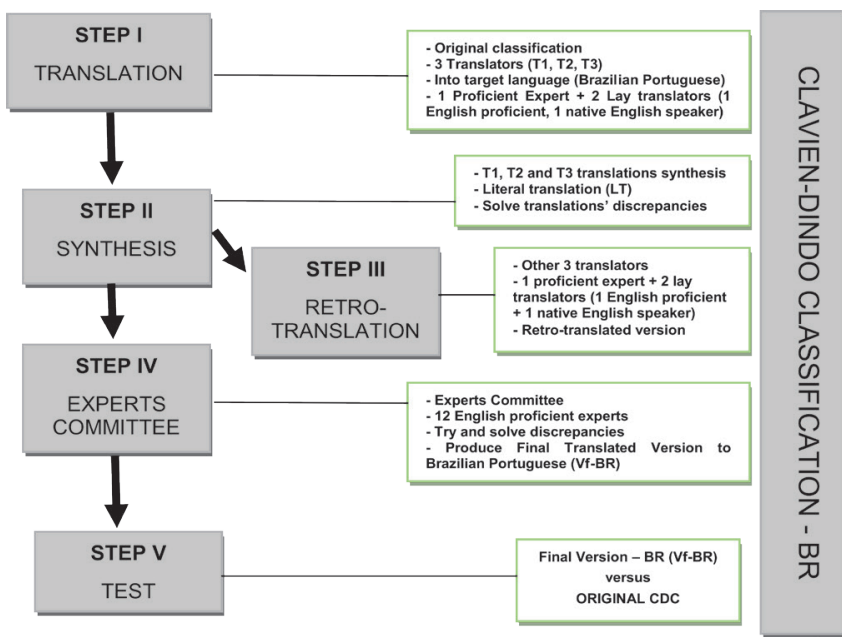

Figure 1. Graphical representation of the methodology applied in the process of translation and Intercultural Adaptation of the Clavien-Dindo Classification of Surgical Complications, source instrument for obtaining the target instrument, $C D C-B R$. Adapted from Beaton et al., 2000. 
"Expert" translator (RT1) and two "Lay" translators, one with English as mother tongue (RT2) and the other proficient in English (RT3). Each translator produced a back-translated version of the LT. The RT1 gathered, compared and synthesized the produced versions, generating a back-translated version (BTV). At this stage, they generated the equivalent $L T$ in relation to the source device, CDC.

\section{- Stage IV (Expert Committee)}

Twelve "Experts" of different surgical specialties of from the departments of General Surgery (3), Surgical Oncology (3), Vascular Surgery (1), Pediatric Surgery (1), Thoracic Surgery (2) and Coloproctology surgery (2) of the Hospital de Clínicas de Porto Alegre (HCPA), all familiar with the CDC and proficient in English, integrated this Committee. This stage was meant to adjust the differences identified in the previous ones, seeking to consolidate the semantic, idiomatic, experiential and conceptual equivalence of the target instrument, generating the translated Final Version (TFV), which we called CDC-US, then forwarded to the validation test (Table 1) .

\section{- Stage V (TFV Test - CDC-BR)}

The TFV (CDC-BR) test was conducted at the Department of General Surgery of the HCPA between October and December 2013. We created two groups, randomly distributed, with 76 participating surgeons. We segregated the surgeons in three different levels of experience (Residents, HCPA Staffs Surgeons with at least ten years as specialists, and Senior Surgeons, Medical School professors from the Universidade Federal do Rio Grande do Sul - UFRGS). Group I $(n=36)$ received the original CDC, and Group II $(n=40)$ received the CDC-BR, both to classify 15 hypothetical clinical cases of surgical complications originating from Dindo et al. and Clavien et al. publications, and translated into Portuguese by the Experts Committee coordinator, (LFM)3,12 (Table 2). All participants were provided a list of examples of surgical complications as published by Dindo et al. ${ }^{3}$, translated by

Table 1. Classification of Surgical Complications of Clavien-Dindo - Brazilian Portuguese version (CDC-BR).

\begin{tabular}{|c|c|c|}
\hline Grau de Classificação & \multicolumn{2}{|r|}{ Definição } \\
\hline Grau I & \multicolumn{2}{|c|}{$\begin{array}{l}\text { - Qualquer desvio do curso pós-operatório Ideal sem necessidade de tratamento } \\
\text { farmacológico ou de intervenções cirúrgicas, endoscópicas, e radiológicas } \\
\text { - Regimes terapêuticos permitidos são: drogas antieméticas, antipiréticos, analgésicos, } \\
\text { diuréticos, eletrólitos, e fisioterapia. Esta categoria também inclui feridas operatórias } \\
\text { drenadas à beira do leito }\end{array}$} \\
\hline Grau II & \multicolumn{2}{|c|}{$\begin{array}{l}\text { - Requer tratamento farmacológico com drogas diferentes daquelas permitidas para } \\
\text { complicações grau I } \\
\text { - Transfusão sanguínea e nutrição parenteral total também estão incluídas }\end{array}$} \\
\hline \multirow{2}{*}{ Grau III } & \multirow{2}{*}{$\begin{array}{l}\text { Exige intervenção cirúrgica, } \\
\text { endoscópica ou intervenção } \\
\text { radiológica }\end{array}$} & III a. Intervenção sem anestesia geral \\
\hline & & III b. Intervenção sob anestesia geral \\
\hline \multirow[t]{2}{*}{ Grau IV } & \multirow{2}{*}{$\begin{array}{l}\text { Complicação com Risco de } \\
\text { vida (incluindo SNC) * } \\
\text { Necessidade de UTI }\end{array}$} & IV a. Disfunção de um só órgão (incluindo diálise) \\
\hline & & IV b. Disfunção de múltiplos órgãos \\
\hline Grau V & \multicolumn{2}{|l|}{ Morte do Paciente } \\
\hline Sufixo "d" & \multicolumn{2}{|c|}{$\begin{array}{l}\text { Se o paciente persiste com uma complicação no momento da alta o sufixo "d" (para } \\
\text { "Deficiência") é adicionado para o respectivo grau de complicação. Esta marca indica a } \\
\text { necessidade de seguimento futuro para avaliar completamente a complicação }\end{array}$} \\
\hline
\end{tabular}

*Hemorragia encefálica, AVC isquêmico, sangramento subaracnoideo, mas exclui acidentes isquêmicos transitórios.

Traduzida e adaptada segundo metodologia divulgada por Beaton et al., em 2000. Instrumento fonte: Dindo D, Demartines N, Clavien PA. Classification of surgical complications: a new proposal with evaluation in a cohort of 6336 patients and results of a survey. Ann Surg. 2004;240(2):205-13. 
Table 2. Distribution of the sample members according to groups and the level of experience of surgeons.

\begin{tabular}{lccc}
\hline \multirow{2}{*}{ Groups } & \multicolumn{3}{c}{ Characteristics of the sample } \\
\cline { 2 - 4 } & \multicolumn{4}{c}{ Classification of surgical complications } & Total \\
\hline Residents & 17 & CDC-BR & 39 \\
Staff & 16 & 22 & 30 \\
Professors & 3 & 14 & 7 \\
Total & 36 & 4 & 76 \\
\hline
\end{tabular}

Distribution of participants between groups and subdivided according to their level of experience.

LFM under the endorsement of the Experts Committee, as a reference in the classification of clinical cases.

\section{- Statistical analysis}

Demographic data and the sample accuracy performance profile were analyzed by the Shapiro-Wilk test (median calculation) for accuracy, Mann-Whitney test (performance relationship between grades, the suffix " $d$ " alone and overall performance) and the Kruskal-Wallis test (performance between groups of different surgeons experience levels). For all analyzes we considered a 95\% confidence interval. The calculation tool was the SPSS software, version 17.0, Chicago, IL.

\section{RESULTS}

The members of Group II, $\mathrm{n}=40$ (translated version, (DC-BR), obtained a better performance, with $85 \%$ accuracy, compared to $79 \%$ of Group I, n $=36$ (original CDC in English). When subjected to the Mann-Whitney test for the analysis of the total number of hits, we obtained a value of $p=0.012$ (Figure 2). Considering the complication Grade, Group I presented a median 13 [11.75-14], maximum 14 versus median 13 [12-14] Maximum 15) in Group II (NS). When analyzing the suffix "d", Group 1 had median 14 [14-15], maximum 15, and Group II, median 15 [14-15], maximum 15, $p=0.05$. In the full analysis, Group I presented median 12 [11.5-14], maximum 15, and Group II, median 13 [11-13], maximum 15, $p=0.012$ (Figure 3). When we considered the surgeons experience level, the accuracy among Group ॥ CDC-BR was higher among residents (87\%) and HCPA Staff (83\%). However, the hit rate among the UFRGS Professors was higher for Group I, who used the original CDC in English (Figure 2). We applied the Kruskal-Whallis test to assess whether there was difference when considering the level of experience of surgeons distributed between groups. The test showed that the performance between the groups was not changed by the level of experience among residents, Staff and Professors (Table 3).

\section{DISCUSSION}

Among the possible outcomes, surgical complications stand out as the indicator most commonly used to assess the quality of surgical treatments ${ }^{22}$. They have great influence on well-being and quality of life of patients, and great impact on the cost of hospitalizations ${ }^{3}$. For decades, many authors have pursued a systematic and standardized form of reporting surgical outcomes ${ }^{23}$. Such efforts date back to the first decade of the 1900s, when Ernest Amory Codman, one of the founders of the American College of Surgeons, started what was after defined as "End Result", or results medicine. He dedicated his life to the systematic account of his surgical results, prompting the comparison between surgeons, treatment modalities and institutions. For these reasons, Codman is considered a "Quality Martyr" and one of the

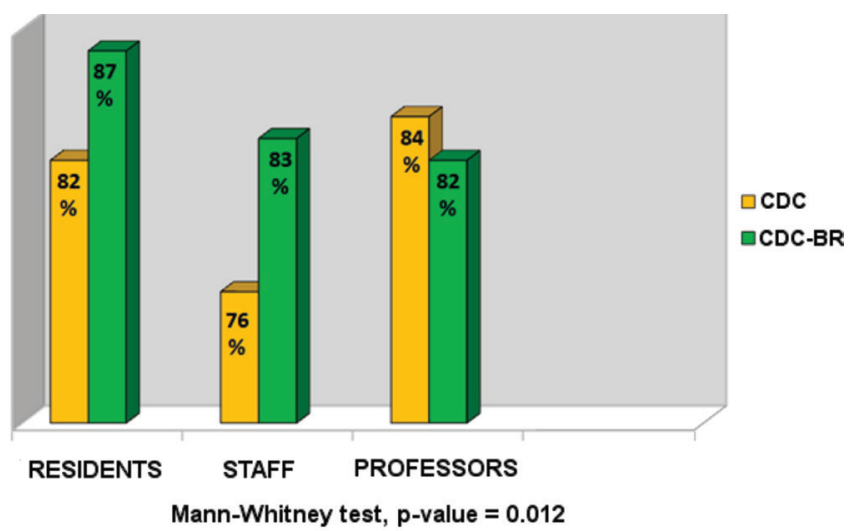

Figure 2. Representation of the percentage of correct answers between groups according to surgeons level of experience. Mann-Whitney test $p<0.05$ for significance. 
Table 3. Comparison of performance between groups and the level of experience of surgeons. (NS).

\begin{tabular}{lccc}
\hline & \multicolumn{3}{c}{ Kruskal-Wallis test } \\
\cline { 2 - 4 } \multicolumn{1}{c}{ Groups } & Group I - CDC (\%) & Classification of surgical complications \\
\hline Residents & 82 & Group II - CDC-BR (\%) & Overall performance (\%) \\
Staff & 76 & 87 & 84 \\
Professors & 84 & 83 & 79 \\
p-value & 0.171 & 82 & 83 \\
\hline
\end{tabular}

There was no difference between the groups as for the level of experience of surgeons.

forerunners of Evidence-Based Medicine (EBM) ${ }^{26-28}$. Despite the efforts of several authors to follow the concepts of EBM, there are, however, still great inconsistency in the reports of adverse events between researchers and hospital records. The absence of consensus on the best way to report and define surgical complications certainly hampers the proper comparison of performance between surgeons, teams, treatment modalities, institutions and possibly advances in the surgical field ${ }^{3,12,23}$.

In 1992, Clavien et al. published a standardized classification for reporting surgical complications, with four levels of severity, based on the therapeutic intervention applied to treat the complications ${ }^{2}$. In 2004, Dindo et al. reviewed the classification proposed by Clavien, based on the same principles of applied therapy, modifying it to five levels of severity. Tests with a large cohort of patients involved ten surgical services around the world assessing its acceptance and reproducibility ${ }^{3}$. This was the first validation of the classification proposed by Dindo. In 2009, Clavien et al. held a new test on the classification

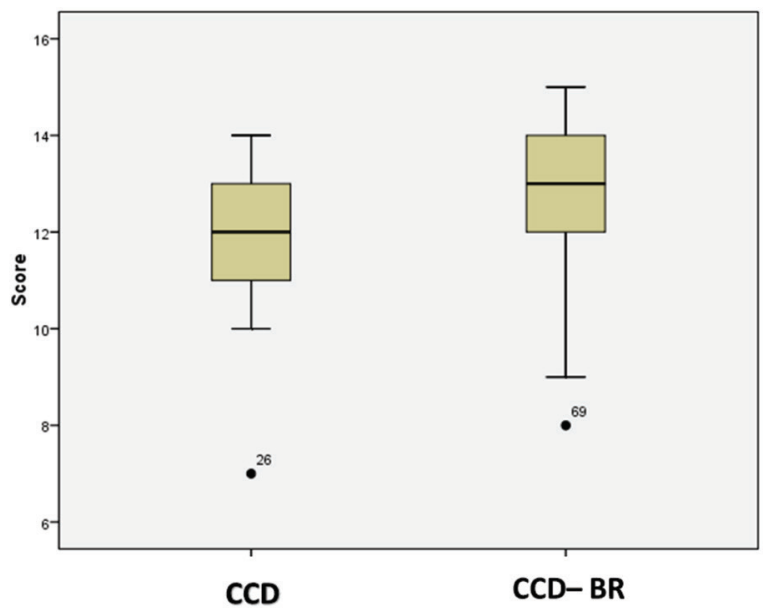

Figure 3. Box plot with representation of the median of the correct answers in the full analysis between groups. There is better accuracy of the group using the translated version, $C D C-B R$. modified by Dindo et al. through a systematic review to assess the number of citations in the literature and the degree of perception from the non-specialists, nurses and patients, point of view. Since then, it is referred to as Clavien-Dindo classification (CDC) for reporting surgical complications $^{12}$.

Since 2004, the CDC system has been cited by nearly three thousand publications, and validated in hundreds of studies in several surgical specialties $9,13,16,1820,22,23,29,30$, allowing the comparison of surgical outcomes of different institutions with greater accuracy, as well as a better communication between surgeons worldwide. The application of this methodology has facilitated the production of multi-center studies and the conduction of systematic reviews ${ }^{23}$. Despite the CDC wide acceptance, some authors have proposed changes in order to adapt it to the reality of their specialties ${ }^{19,20,22,23}$.

Slankamenac et al. and Marcondes et al. discussed the need for translation adjustment and intercultural adaptation of the CDC when applied from the perspective of patients, since literal translations can tarnish semantic, idiomatic and conceptual features of features originally made and tested in German and English $^{2,3,9,12,13,25}$. In this context, we consider that there is a clear demand for translation and intercultural adaptation of the CDC into other languages. Thus, a standardized system for the classification of postoperative complications should be simple, reproducible, flexible and applicable in different cultures, without language and cultural barriers ${ }^{20}$. The definitions must be clear, taking into account the specific vocabulary in different languages and cultures ${ }^{23}$.

With the growing trend in conducting multicenter studies, there is a clear need for appropriate methodology application for the translation and cultural adap- 
tation of questionnaires and/or tools used in the research field. The validation test aims to maintain equivalence between the versions of origin and destination, maintaining the instrument's reliability24,31,32.

Although considered a useful tool for generating evidence on the quality of surgical treatments, the CDC had not been translated into Brazilian Portuguese, nor tested. Therefore, our study used the methodology published by Beaton et al., in 2000, for the process of translation and cultural adaptation of performance assessment tools in health care and quality of life ${ }^{24}$ (Figure 1). All stages were followed so that the translation and cultural adaptation process reached the most of semantic, idiomatic, experimental and conceptual equivalence between the origin (CDC) instrument and the destination (CDC-BR) one.

During the translation stages I and II, all discrepancies were identified and corrected. In stage III, Back-translation, we could note that the produced versions were very close to the source instrument, CDC, which confirmed the good quality of the translation process. In stage IV, the Experts Committee noted that to translate the suffix " $d$ " from the original instrument, there was a discrepancy between the literal translation and the meaning of the word. In English, the word "disability" has its literal translation as "incapacidade". The Experts Committee decided to keep the letter " $d$ ", as provided in the original CDC; the word with greater semantic equivalence with the instrument source is "deficiência". The function of the Experts Committee (Stage IV) is therefore crucial to maintaining linguistic and cultural equivalence.

The CDC-BR was tested in order to validate it as a faithful instrument for application. The test showed an index of correct answers of $85 \%$ for Group II, who used CDC-BR (translated version), versus 79\% for Group I, who used CDC (original version), Mann-Whitney displaying $p=0.012$, therefore significant. This result reflects that the methodology applied in the translation process was successful. We noted that the level of surgeons experience did not influence performance in assessing the clinical cases presented, in accordance with data shown in the literature ${ }^{3,9,12,13}$. We found in our sample, however, that the performance of professors was higher in Group I, which used the original CDC, which can be attributed to higher English proficiency by professors.

Dindo et al. found accuracies ranging from $86 \%$ to $93 \%$ when the test was applied to 144 surgeons with different levels of experience in ten centers around the world. Clavien et al. sent 11 difficult example cases to seven centers in different continents, in which CDC had routinely been used. Accuracy ranged from $89 \%$ to $100 \%$. In both publications, the CDC has been described as a simple, objective and reproducible manner for assessment of surgical outcomes, likely to be used by surgeons in different levels of experience ${ }^{3,9,12}$. In our study, we observed that the CDC$B R$, when tested, has similar performance to the one presented in publications that tested and validated the previously CDC ${ }^{3,12}$ (Figure 4).

This study shows that there was proper translation and cultural adaptation of the Brazilian version of the CDC. The CDC-BR has proven to be reliable and now may be a useful tool for generating evidence about the surgical outcomes between teams, institutions and treatment modalities. Therefore, we recommend the wide dissemination of CDC-BR among surgeons from various specialties in our country. In the future, this could facilitate the achievement of better benchmarks, so that protocols that are more appropriate can be applied in research on morbidity and quality control for the surgical treatment and care.

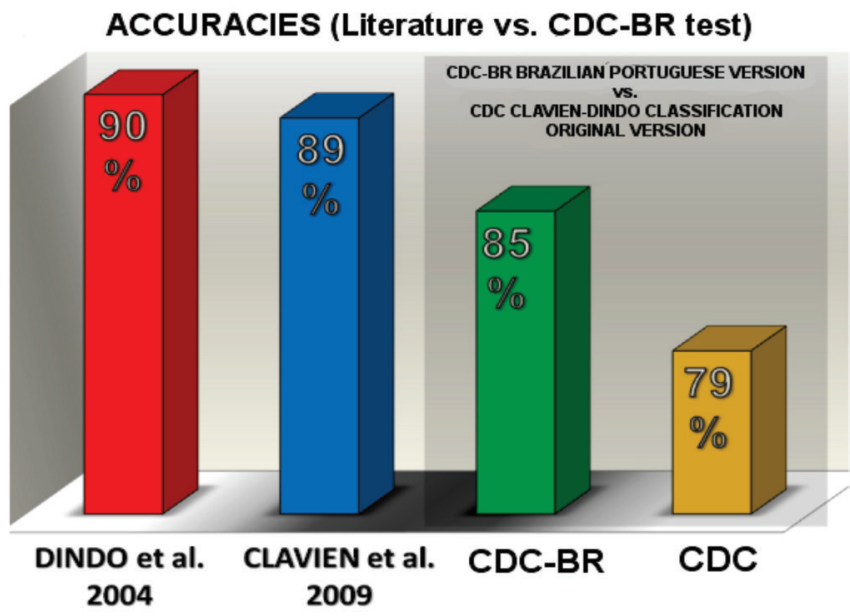

Figure 4. Percentages of correct answers of CDC-BR test compared with the results reported in the literature. 


\section{R E S U M O}

Objetivo: gerar uma versão traduzida e validada da Classificação de Complicações Cirúrgicas de Clavien-Dindo (CCD) para o Português-Brasileiro (CCD-BR). Métodos: o processo de tradução e adaptação seguiu a diretriz de Beaton et al., de 2000. Formaram-se dois grupos, Grupo I, que utilizou a versão original (CCD, $n=36$ ) testado em relação ao Grupo II, com a versão modificada (CCD-BR, $n=40)$, com um total de 76 cirurgiões participantes em níveis de experiência distintos do Departamento de Cirurgia do Hospital de Clínicas de Porto Alegre. Quinze casos clínicos de complicações cirúrgicas foram classificados em cada grupo. Comparou-se o desempenho entre grupos (teste de Mann-Whitney) relacionando ao nível de experiência dos cirurgiões (teste de Kruskal-Wallis). Valor de $p<0,05$ como significativo. Resultados: o desempenho do Grupo II (CCD-BR) foi superior, com 85\% de acertos, contra 79\% do Grupo I (CCD), $p$-valor=0,012 do teste de Mann-Whitney. O desempenho dos grupos em relação à experiência dos cirurgiões foi p-valor=0,171 para o Grupo l, $p$-valor=0,528 para o Grupo Il, e p-valor=0,135 para o desempenho geral, teste de Kruskal-Wallis. Conclusão: foi produzida uma versão traduzida e validada da CCD para o Português-Brasileiro. O instrumento produzido será ferramenta útil na produção de evidências sobre os resultados cirúrgicos.

Descritores: Cirurgia/Complicações. Melhoria de Qualidade. Validação de Dados. Avaliação de Resultados (Cuidados de Saúde). Morbidade.

\section{REFERENCES}

1. Dindo D, Clavien PA. What is a surgical complication? World J Surg. 2008;32(6):939-41.

2. Clavien PA, Sanabria JR, Strasberg SM. Proposed classification of complications of surgery with examples of utility in cholecystectomy. Surgery. 1992;111(5):518-26.

3. Dindo D, Demartines N, Clavien PA. Classification of surgical complications: a new proposal with evaluation in a cohort of 6336 patients and results of a survey. Ann Surg. 2004;240(2):205-13.

4. Birkmeyer JD, Dimick JB, Birkmeyer NJ. Measuring the quality of surgical care: structure, process, or outcomes? J Am Coll Surg. 2004;198(4):626-32.

5. Vonlanthen R, Clavien PA. What factors affect mortality after surgery? Lancet. 2012;380(9847):1034-6.

6. Brennan MF, Radzyner M, Rubin DM. Outcomemore than just operative mortality. J Surg Oncol. 2009;99(8):470-7.

7. Dimick JB, Weeks WB, Karia RJ, Das S, Campbell DA Jr. Who pays for poor surgical quality? Building a business case for quality improvement. J Am Coll Surg. 2006;202(6):933-7.

8. Finks JF, Osborne NH, Birkmeyer JD. Trends in hospital volume and operative mortality for high-risk surgery. N Engl J Med. 2011;364(22):2128-37.

9. Slankamenac K, Graf R, Barkun J, Puhan MA, Clavien PA. The comprehensive complication index: a novel continuous scale to measure surgical morbidity. Ann Surg. 2013;258(1):1-7.
10. Healey MA, Shackford SR, Osler TM, Rogers FB, Burns E. Complications in surgical patients. Arch Surg. 2002;137(5):611-7; discussion 617-8.

11.Strasberg SM, Linehan DC, Clavien PA, Barkun JS. Proposal for definition and severity grading of pancreatic anastomosis failure and pancreatic occlusion failure. Surgery. 2007;141(4):420-6.

12. Clavien PA, Barkun J, de Oliveira ML, Vauthey JN, Dindo $D$, Schulick RD, et al. The Clavien-Dindo classification of surgical complications: five-year experience. Ann Surg. 2009;250(2):187-96.

13.Slankamenac K, Graf R, Puhan MA, Clavien PA. Perception of surgical complications among patients, nurses and physicians: a prospective cross-sectional survey. Patient Saf Surg. 2011;5(1):30.

14.Guillemin F, Bombardier C, Beaton D. Cross-cultural adaptation of health-related quality of life measures: literature review and proposed guidelines. J Clin Epidemiol. 1993;46(12):1417-32.

15. Sink EL, Leunig M, Zaltz I, Gilbert JC, Clohisy J; Academic Network for Conservational Hip Outcomes Research Group. Reliability of a complication classification system for orthopaedic surgery. Clin Orthop Relat Res. 2012;470(8):2220-6.

16.Perisanidis C, Herberger B, Papadogeorgakis $N$, Seemann R, Eder-Czembirek C, Tamandl D, et al. Complications after free flap surgery: do we need a standardized classification of surgical complications? Br J Oral Maxillofac Surg. 2012;50(2):113-8. 
17. Rassweiler JJ, Rassweiler MC, Michel MS. Classification of complications: is the Clavien-Dindo classification the gold standard? Eur Urol. 2012;62(2):256-8; discussion 259-60.

18.Petruzziello A, Kondo W, Hatschback SB, Guerreiro JA, Filho FP, Vendrame $C$, et al. Surgical results of pelvic exenteration in the treatment of gynecologic cancer. World J Surg Oncol. 2014;12:279.

19.Baker MS, Sherman KL, Stocker SJ, Hayman AV, Bentrem DJ, Prinz RA, et al. Using a modification of the Clavien-Dindo system accounting for readmissions and multiple interventions: defining quality for pancreaticoduodenectomy. J Surg Oncol. 2014;110(4):400-6.

20.Lee KG, Lee HJ, Yang JY, Oh SY, Bard S, Suh YS, et al. Risk factors associated with complication following gastrectomy for gastric cancer: retrospective analysis of prospectively collected data based on the Clavien-Dindo system. J Gastrointest Surg. 2014;18(7):1269-77.

21. Graefen M. The modified Clavien system: a plea for a standardized reporting system for surgical complications. Eur Urol. 2010;57(3):387-9.

22.Ivanovic J, Seely AJ, Anstee C, Villeneuve PJ, Gilbert S, Maziak DE, et al. Measuring surgical quality: comparison of postoperative adverse events with the American College of Surgeons NSQIP and the Thoracic Morbidity and Mortality classification system. J Am Coll Surg. 2014;218(5):1024-31.

23. Kazaryan AM, Røsok BI, Edwin B. Morbidity assessment in surgery: refinement proposal based on a concept of perioperative adverse events. ISRN Surg. 2013;2013:625093.

24. Beaton DE, Bombardier C, Guillemin F, Ferraz MB. Guidelines for the process of cross-cultural adaptation of self-report measures. Spine. 2000;25(24):3186-91. 25. Marcondes FB, Vasconcelos RA, Marchetto A, Andrade ALL, Zoppi Filho A, Etchebehere M. Tradução e adaptação cultural do Rowe score para a língua portuguesa. Acta ortop bras. 2012;20(6):346-50.

26. Neuhauser D. Ernest Amory Codman MD. Qual Saf Health Care. 2002;11(1):104-5.

27. Greene AK, May JW Jr. Ernest Amory Codman, M.D. (1869 to 1940): the influence of the End Result Idea on plastic and reconstructive surgery. Plast Reconstr Surg. 2007;119(5):1606-9.

28. Brand RA. Biographical sketch: Ernest Amory Codman, MD (1869-1940). Clin Orthop Relat Res. 2013;471(6):1775-7. 29. Mitropoulos D, Artibani W, Graefen M, Remzi M, Rouprêt M, Truss M; European Association of Urology Guidelines Panel. Reporting and grading of complications after urologic surgical procedures: an ad hoc EAU guidelines panel assessment and recommendations. Eur Urol. 2012;61(2):341-9.

30.Yoon PD, Chalasani V, Woo HH. Use of Clavien-Dindo classification in reporting and grading complications after urological surgical procedures: analysis of 2010 to 2012. J Urol. 2013;190(4):1271-4.

31.Guillemin F, Bombardier C, Beaton D. Cross-cultural adaptation of health-related quality of life measures: literature review and proposed guidelines. J Clin Epidemiol. 1993;46(12):1417-32.

32. Cook C, Richardson JK, Braga L, Menezes A, Soler X, Kume $\mathrm{P}$, et al. Cross-cultural adaptation and validation of the Brazilian Portuguese version of the Neck Disability Index and Neck Pain and Disability Scale. Spine. 2006;31(14):1621-7.

Recebido em: 18/12/2015

Aceito para publicação em: 17/03/2016

Conflito de interesse: nenhum.

Fonte de financiamento: nenhuma.

\section{Endereço para correspondência:}

Luis Fernando Moreira

E-mail: lufmoreira@hcpa.edu.br / Ifmoreiramd@gmail.com 